\title{
Lymphedema following breast cancer: The importance of surgical methods and obesity
}

\author{
Rebecca J Tsai ${ }^{1 *}$, Leslie K Dennis ${ }^{1,2}$, Charles F Lynch ${ }^{1}$, Linda G Snetselaar ${ }^{1}$, Gideon KD Zamba and Carol Scott-Conner $^{4}$ \\ ${ }^{1}$ Department of Epidemiology, College of Public Health, University of Iowa, Iowa City, IA, USA \\ ${ }^{2}$ Division of Epidemiology and Biostatistics, College of Public Health, University of Arizona, Tucson, AZ, USA \\ ${ }^{3}$ Department of Biostatistics, College of Public Health, University of Iowa, Iowa City, IA, USA \\ ${ }^{4}$ Department of Surgery, College of Medicine, University of Iowa, Iowa City, IA, USA
}

\begin{abstract}
Background: Breast cancer-related arm lymphedema is a serious complication that can adversely affect quality of life. Identifying risk factors that contribute to the development of lymphedema is vital for identifying avenues for prevention. The aim of this study was to examine the association between the development of arm lymphedema and both treatment and personal (e.g., obesity) risk factors.
\end{abstract}

Methods: Women diagnosed with breast cancer in Iowa during 2004 and followed through 2010, who met eligibility criteria, were asked to complete a short computer assisted telephone interview about chronic conditions, arm activities, demographics, and lymphedema status. Lymphedema was characterized by a reported physiciandiagnosis, a difference between arms in the circumference $(>2 \mathrm{~cm}$ ), or the presence of multiple self-reported arm symptoms (at least two of five major arm symptoms, and at least four total arm symptoms). Relative risks (RR) were estimated using logistic regression.

Results: Arm lymphedema was identified in 102 of 522 participants (19.5\%). Participants treated by both axillary dissection and radiation therapy were more likely to have arm lymphedema than treated by either alone. Women with advanced cancer stage, positive nodes, and larger tumors along with a body mass index $>40$ were also more likely to develop lymphedema. Arm activity level was not associated with lymphedema.

Conclusions: Surgical methods, cancer characteristics and obesity were found to contribute to the development of arm lymphedema. Vigorous arm activity postsurgery was not found to increase the risk of arm lymphedema.

Abbreviations: BMI: Body Mass Index; CATI: Computer-Assisted Telephone Interviewing; ICR: Iowa Cancer Registry; RR: Relative Risk; CI: Confidence Interval

\section{Introduction}

In the United States, breast cancer is the most common cancer excluding non-melanoma skin cancers among women [1]. It is estimated that 266,120 women will be diagnosed with breast cancer in 2018 , $90 \%$ of whom will survive from breast cancer at least five years $[2,3]$. Lymphedema of the arm (here forward referred to as lymphedema) is believed to be a treatment complication that adversely affects breast cancer survivors. However, there is conflicting information regarding which treatments are risk factors and limited research on other risk factors for lymphedema. Lymphedema causes the accumulation of fluid (swelling) in the arm and $15-20 \%$ of breast cancer survivors are expected to develop this condition in their lifetimes [4]. Lymphedema is a progressive disease; if not treated and controlled, severe pain and disability can result.

Lymphedema research evaluating treatment or personal risk factors has yielded conflicting results. Guidelines that warned breast cancer survivors against vigorous or repetitive exercise [5] are now being challenged by recent evidence disputing the previously reported harm of vigorous arm activities [6-11].

This study looked at the association between the development of lymphedema and treatment and personal (e.g. obesity, arm activity) risk factors among a cohort of women diagnosed with breast cancer in Iowa during 2004 and followed through 2010 for symptoms of lymphedema. This study attempted to examine arm exercise in multiple ways.

\section{Materials and Methods}

Breast cancer cases were identified through the Iowa Cancer Registry (ICR). The ICR is a population-based registry that is part of the National Cancer Institute's Surveillance Epidemiology and End Results (SEER) program. A total of 2164 breast cancer cases were diagnosed among Iowa residents during 2004. Ineligible subjects included 9 males, 236 women over age 80 at breast cancer diagnosis, and 145 cases known to be deceased. We excluded breast cancer cases who had a previous or subsequent cancer diagnosis $(\mathrm{N}=323)$, or had more than one primary tumor at time of initial breast cancer diagnosis $(\mathrm{N}=174)$ except for insitu cervical cancer or non-melanoma skin cancer. Due to low 5-year survival, stage IV breast cancer cases $(\mathrm{N}=76)$ were also excluded. A total of 1,201 met our inclusion criteria. The interview was completed by 522

*Correspondence to: Rebecca Tsai, National Institute for Occupational Safety and Health, 1090 Tusculum Ave, R-17, Cincinnati, OH 45226, USA, Tel: (513)841-4398, Fax: (513) 841-4489, E-mail: rtsai@cdc.gov

Key words: arm activity, arm lymphedema, body mass index, breast cancer comorbidity, surgery

Received: May 01, 2018; Accepted: May 28, 2018; Published: May 31, 2018 
(43.5\%) eligible women with a participation rate among those we were able to contact of $50.6 \%(522 / 1,020)$. Participants that were unstaged $(\mathrm{N}=17)$ were not included in the staging analysis as only stages I to III were compared, but were included in analyses for treatment and sociodemographic factors. The Institutional Review Board at the University of Iowa has approved this study.

\section{Recruitment}

Physicians of subjects were first contacted to see if there were any reasons why the woman should not be approached for this study. Physician consent was assumed if the physician did not contact the ICR within three weeks, per ICRs standard passive consent policy. Thereafter, an invitation letter with elements of consent (as required by the Institutional Review Board at the University of Iowa) was sent to each woman. Two weeks after mailing the letters, a trained interviewer called the subjects. Subjects received up to 10 call attempts on different days of the week and at different times of the day. Subjects were traced for addresses or phone numbers through internet sources as needed.

The ICR provided information for demographic, disease- and treatment-related factors. These included date of birth, date of breast cancer diagnosis, laterality of cancer, tumor size, cancer stage, number of lymph nodes examined, scope of lymph node dissection, number of positive lymph nodes found, number of lymph nodes removed, date and type of first-course therapy (surgery, chemotherapy, radiation and hormone therapy), and surgery type.

\section{Participant interview}

The interview was designed to collect information not available through the ICR records. We used cognitive interviewing and piloting to develop the questionnaire. Rewording and reformatting of questions were done to clarify and facilitate the interviewing process. Computerassisted telephone interviewing (CATI) was used to allow for data checks during the interview to minimize data entry errors. The average time of interview was 17 minutes. Demographic information collected included marital status, highest level of education, hand dominance, and self-reported height and weight to calculate body mass index (BMI) at time of diagnosis. Radiation therapy to the axilla was also selfreported.

Self-reported lymphedema was collected through the CATI in three different ways. First, subjects were asked if they were ever diagnosed by a physician with lymphedema. If diagnosed with lymphedema, they were also asked whether or not it had resolved. Second, they were asked if they experienced 13 specific arm/hand symptoms within the last three months (Table 1). Third, they were asked to measure the arm circumference of both arms at two different locations (one hand width above and below the elbow crease). Subjects were also asked if they used specific methods at least once a week to treat or prevent lymphedema. Additional information was collected on arm infection, chronic conditions diagnosed prior to breast cancer diagnosis/and or arm lymphedema diagnosis (e.g., high blood pressure, high cholesterol, heart attack, coronary heart disease, stroke, congestive heart failure, emphysema, chronic bronchitis, asthma, thyroid condition, liver condition, kidney failure, osteoporosis, diabetes, and arthritis), airplane trips taken the year after breast cancer diagnosis, lifting heavy objects, and physical therapy.

A portion of the interview focused on specific arm activities (swimming, playing tennis, weightlifting, and gardening) and overall arm activity levels. Overall arm activities were broken down into four combinations based on the positioning (above or below the shoulders)
Table 1: Distribution of self-reported lymphedema assessments among study participants diagnosed with breast cancer in Iowa, 2004

\begin{tabular}{|l|c|c|}
\hline & Participants & \% \\
\hline Physician-diagnosed lymphedema & $\mathrm{N}=522$ & \\
\hline Unresolved & & 84 \\
\hline Resolved & 28 & 5.4 \\
\hline Not diagnosed & 450 & 86.2 \\
\hline & & \\
\hline Arm measurement & 49 & 9.4 \\
\hline$>2$ cm difference between arms & 351 & 67.2 \\
\hline$\leq 2$ cm difference between arms & 122 & 23.4 \\
\hline Missing & & \\
\hline & & \\
\hline Arm symptoms* & 45 & 91.4 \\
\hline Subjective indication of arm lymphedema & 477 & \\
\hline No subjective indication of arm lymphedema & & 80.5 \\
\hline & & \\
\hline Arm lymphedema based on any of the above & 420 & \\
\hline Arm lymphedema & & \\
\hline No arm lymphedema & & \\
\hline
\end{tabular}

*Subjective indication is present if subject has at least 2 major symptoms (shirt sleeve felt tight, arm felt swollen, heavy, tense or hard) and at least 4 total symptoms (major arm symptoms plus arm felt numb, stiff, or painful, rash on arm, other arm symptoms, cannot see knuckles or veins on hand, or rings felt tight)

and the intensity (vigorous or moderate) of the arm activity. Each subject was asked to estimate the number of hours per week for each combination of arm activity during 1) the past year, 2) one year prior to breast cancer diagnosis, and 3 ) one year after the subject was able to resume routine household activities. The frequency and the intensity of arm activities were later combined into low, medium and high levels. High level was defined as doing vigorous arm activities for more than two hours per week. Low level was defined as doing vigorous arm activities for less than one hour per week and doing moderate arm activities for two or less hours per week.

\section{Lymphedema categorization}

Lymphedema was characterized in 3 different ways; 1) physiciandiagnosed, not resolved, 2) the circumference of the affected arm was greater than $2 \mathrm{~cm}$ larger than the other arm (either above or below the elbow crease), or 3) the presence of multiple self-reported arm symptoms. For arm symptoms, a woman must have reported at least two of five major arm symptoms (shirt sleeve felt tight, arm felt swollen, heavy, tense or hard) and at least four total arm symptoms (major symptoms plus arm felt numb, stiff, or painful, rash on arm, other arm symptoms, cannot see knuckles or veins on hand, or rings felt tight). The arm symptoms definition was determined based on the experience of our expert panel. In this report a woman was considered to have lymphedema if she had a positive indication of lymphedema based on any of the three assessment criteria. The distribution of lymphedema status based on these 3 criteria is reported in Table 1.

\section{Reliability and representativeness}

We examined reliability of the telephone interview among 19 subjects with lymphedema and 20 subjects without lymphedema (based on the initial interview). The second interview was approximately 6 weeks after the initial interview. Kappa coefficients ranged between 0.40.8 for most items, which indicated fair to good agreement.

No significant differences between participants and nonparticipants were found for disease characteristics and breast cancer 


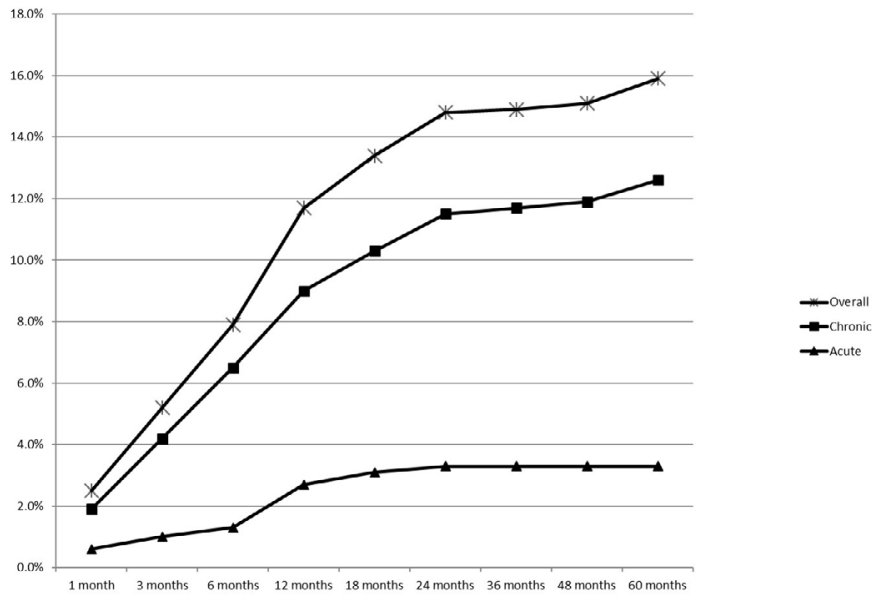

Figure 1: Cumulative Incidence of Arm Lymphedema diagnosed by a physician or by having $4+$ symptoms among breast cancer survivors in Iowa, 2004

treatments, indicating that the study results may be generalized to breast cancer cases diagnosed in Iowa during 2004.

\section{Statistical analysis}

Univariate relative risk estimates (RRs) with 95\% confidence intervals (95\% CI) were calculated using unconditional logistic regression. Potential confounders were identified prior to analysis based on biologic plausibility. Estimates were adjusted for confounders that conferred a $10 \%$ or greater change from the crude RR. For factors of interest in which less than 20 subjects indicated they had the condition, confounders that presented a $>20 \%$ change from the crude RR were adjusted for in the final model.

\section{Results}

\section{Cumulative incidence of lymphedema}

Arm lymphedema subsequent to breast cancer treatment was identified in $102(19.5 \%)$ participants. The time between initial breast cancer treatment and onset of arm symptoms or physician-diagnosed lymphedema are graphed in Figure 1. The majority of lymphedema cases was persistent cases, and was diagnosed within two years after the initial breast cancer treatment.

\section{Participants' characteristics}

At the time of interview, the average age of participants was 63 years and the mean BMI was $28.8 \mathrm{~kg} / \mathrm{m}^{2}$. One-third (30.5\%) of participants were college graduates and $70 \%$ were married. Neither education level nor marital status was associated with lymphedema (Table 2). Subjects who were under 50 at the time of interview were more likely to develop lymphedema than subjects aged $75+$ years $(R R=2.95,95 \%$ CI: 1.25 , 6.98). Participants with a BMI $\geq 30(35.9 \%)$ were more likely to develop lymphedema ( $R R=2.15,95 \%$ CI: $1.35,3.42)$ than those with a $\mathrm{BMI}<30$. An increasing trend in the RRs was observed as BMI increased over 30 (Table 2).

\section{Breast cancer disease and treatment}

For cancer characteristics, $87 \%$ of participants were classified as having stage I or II breast cancer and the mean tumor size was $19 \mathrm{~mm}$. In regards to breast cancer surgical treatments, $57 \%$ of women were treated with lumpectomy and $34 \%$ with sentinel node biopsy with an average of 8 nodes removed. Only $30.5 \%$ were detected with positive nodes and no trend was seen with increasing number of positive nodes (data not shown). Participants with $>10$ lymph nodes removed were found to have an increased risk of developing lymphedema in the presence of radiation therapy. However this effect was reduced after adjustment for axillary dissection. Our results observed a trend of increasing risk as an increasing number of nodes was removed. Radiation therapy was received by $63 \%$ of women, and among those who received radiation, 30 stated that radiation was directed to the axillary area as well as the breast. Over half of the participants had chemotherapy and/or hormonal therapy as part of their breast cancer treatment.

Lymphedema was associated with stage III cancer $(\mathrm{RR}=2.23,95 \%$ CI: $1.09,4.55)$, tumors $>30 \mathrm{~mm}(\mathrm{RR}=2.76,95 \% \mathrm{CI}: 1.16,6.58)$, and the presence of positive nodes ( $\mathrm{RR}=1.88,95 \% \mathrm{CI}$ : 1.13, 3.13) (Table 3). Axillary dissection and radiation were found to interact ( $\mathrm{p}=0.01)$. The combination of both axillary dissection and radiation therapy showed a slightly stronger association with lymphedema $(\mathrm{RR}=2.61,95 \% \mathrm{CI}: 1.27$, 5.39) than either axillary dissection ( $R R=2.21,95 \% \mathrm{CI}: 1.32,3.68)$ or radiation alone ( $\mathrm{RR}=1.29,95 \% \mathrm{CI}: 0.81,2.04)$. Radiation directed to the axillary area ( $\mathrm{RR}=1.10,95 \% \mathrm{CI}: 0.62-1.93)$ and other treatment factors were not associated with lymphedema (Table 3 ).

\section{Chronic conditions}

Lymphedema was associated with chronic bronchitis $(\mathrm{RR}=3.45,95 \%$ CI: 1.24, 9.63). A borderline increased risk for developing lymphedema was seen among participants who were diagnosed with osteoarthritis/

Table 2: Relative risk of demographic factors and lymphedema among subjects diagnosed with breast cancer in Iowa, 2004

\begin{tabular}{|c|c|c|c|c|}
\hline & \multicolumn{2}{|c|}{ Lymphedema } & \multicolumn{2}{|c|}{ Adjusted } \\
\hline & Yes & No & $\mathbf{R R}$ & CI \\
\hline \multicolumn{5}{|l|}{ Age at interview } \\
\hline $75-85$ & $12(11.8)$ & $86(20.5)$ & Ref* & \\
\hline $70-74$ & $14(13.7)$ & $56(13.3)$ & 1.85 & $0.75,4.55$ \\
\hline $65-69$ & $16(15.7)$ & $51(12.1)$ & 1.77 & $0.72,4.34$ \\
\hline $60-64$ & $13(12.8)$ & $61(14.5)$ & 1.29 & $0.52,3.18$ \\
\hline $55-59$ & $13(12.8)$ & $60(14.3)$ & 1.40 & $0.56,3.49$ \\
\hline $50-54$ & $14(13.7)$ & $57(13.6)$ & 1.61 & $0.66,3.94$ \\
\hline $25-49$ & $20(19.6)$ & $49(11.7)$ & 2.95 & $1.25,6.98$ \\
\hline Trend RR comparing age $75-85$ to $25-49$ & & & 1.85 & $0.93,3.70$ \\
\hline \multicolumn{5}{|l|}{ Education } \\
\hline$\leq$ High school & $45(44.5)$ & $192(46.0)$ & $\operatorname{Ref}^{\dagger}$ & \\
\hline Some college & $25(24.8)$ & $98(23.5)$ & 0.90 & $0.50,1.63$ \\
\hline$\geq$ College & $31(30.7)$ & $127(30.5)$ & 0.94 & $0.53,1.65$ \\
\hline $\begin{array}{l}\text { Trend RR comparing } \geq \text { College to } \leq \text { High } \\
\text { school }\end{array}$ & & & 0.93 & $0.53,1.64$ \\
\hline \multicolumn{5}{|l|}{ Married } \\
\hline No & $33(33.0)$ & $124(29.5)$ & $\operatorname{Ref}^{\ddagger}$ & \\
\hline Yes & $67(67.0)$ & $296(70.5)$ & 0.76 & $0.46,1.23$ \\
\hline \multicolumn{5}{|l|}{ BMI $\left(\mathbf{k g} / \mathbf{m}^{2}\right)$} \\
\hline$<18.5$ & 0 & $4(1.0)$ & N/A & \\
\hline $18.5-24.9$ & $22(21.8)$ & $138(33.1)$ & Ref* & \\
\hline $25-29.9$ & $28(27.7)$ & $140(33.6)$ & 1.20 & $0.64,2.23$ \\
\hline $30-34.9$ & $20(19.8)$ & $83(19.9)$ & 1.50 & $0.76,2.98$ \\
\hline 35-39.9 & $13(12.9)$ & $35(8.4)$ & 2.51 & $1.12,5.65$ \\
\hline $40+$ & $18(17.8)$ & $17(4.1)$ & 5.58 & $2.45,12.7$ \\
\hline Trend RR comparing $40+$ to $18.5-24.9$ & & & 7.43 & $3.03,18.2$ \\
\hline
\end{tabular}

$\mathrm{RR}=$ relative risk $\mathrm{CI}=$ confidence interval; $\mathrm{BMI}=$ body mass index.

Note: Total number of subjects may not add up to 522 due to missing data

* Adjusted for BMI, axillary dissection, number of lymph nodes removed, any radiation, and any radiation $\mathrm{x}$ axillary dissection

${ }^{\dagger}$ Adjusted for BMI, age, axillary dissection, any radiation, and any radiation $\mathrm{x}$ axillary dissection

${ }^{\ddagger}$ Adjusted for age, axillary dissection, any radiation, and any radiation $\mathrm{x}$ axillary dissection 
rheumatoid arthritis (RR=1.57, 95\% CI: 0.93, 2.67) and/or kidney failure ( $R R=4.70,95 \% \mathrm{CI}: 0.89,24.85)$. No association was found with high blood pressure, diabetes or other conditions reported after adjustment for age, BMI, and the interaction of axillary dissection and radiation.

\section{Arm activity and other personal factors}

No associations were found between lymphedema and specific arm activities including swimming, playing tennis, weightlifting or gardening. When analyses were restricted to participants who had the same level of arm activity before and after breast cancer diagnosis, no association between lymphedema and arm activity level either above or below the shoulders was found (Table 4). Surgery on dominant side $(\mathrm{RR}=1.49,95 \% \mathrm{CI}$ : 0.95-2.32), and air travel ( $\mathrm{RR}=0.98,95 \% \mathrm{CI}$ : 0.63-1.52) were not associated with lymphedema in this study. An association was seen between infection and lymphedema $(R R=8.51$,

Table 3: Relative Risk of Lymphedema by Breast Cancer Treatment and Disease Factors Among Subjects Diagnosed with Breast Cancer in Iowa, 2004

\begin{tabular}{|c|c|c|c|c|}
\hline & \multicolumn{2}{|c|}{ Lymphedema } & \multicolumn{2}{|c|}{ Adjusted } \\
\hline & Yes & No & $\mathbf{R R}$ & CI \\
\hline \multicolumn{5}{|l|}{ Stage } \\
\hline Stage I & $42(42.0)$ & $235(58.2)$ & Ref* & \\
\hline Stage II & $38(38.0)$ & $139(34.4)$ & 1.13 & $0.66,1.92$ \\
\hline Stage III & $20(20.0)$ & $30(7.4)$ & 2.23 & $1.09,4.55$ \\
\hline $\begin{array}{l}\text { Trend RR comparing Stage III to Stage } \\
\text { I }\end{array}$ & & & 1.99 & $0.99,3.98$ \\
\hline \multicolumn{5}{|l|}{ Primary tumor size $(\mathbf{m m})$} \\
\hline $0-9$ & $15(15.8)$ & $106(26.6)$ & $\operatorname{Ref}^{\dagger}$ & \\
\hline $10-14$ & $17(17.9)$ & $88(22.1)$ & 1.26 & $0.57,2.75$ \\
\hline $15-29$ & $39(41.1)$ & $158(39.6)$ & 1.60 & $0.78,3.34$ \\
\hline $30+$ & $24(25.3)$ & $47(11.8)$ & 2.76 & $1.16,6.58$ \\
\hline Trend RR comparing $30+$ to $0-9$ & & & 2.65 & $1.14,6.13$ \\
\hline \multicolumn{5}{|l|}{ Surgery } \\
\hline Lumpectomy & $54(52.9)$ & $243(58.1)$ & $\operatorname{Ref}^{*}$ & \\
\hline Mastectomy & $13(12.8)$ & $56(13.4)$ & 1.09 & $0.39,3.04$ \\
\hline Modified radical mastectomy & $35(34.3)$ & $119(28.5)$ & 1.53 & $0.75,3.15$ \\
\hline \multicolumn{5}{|l|}{ \# of lymph node removed } \\
\hline $0-2$ & $17(16.8)$ & $126(30.4)$ & Ref* & \\
\hline $3-6$ & $21(20.8)$ & $108(26.0)$ & 1.10 & $0.50,2.39$ \\
\hline $7-10$ & $18(17.8)$ & $57(13.73)$ & 1.45 & $0.56,3.78$ \\
\hline$>10$ & $45(44.6)$ & $124(29.9)$ & 1.60 & $0.66,3.84$ \\
\hline Trend RR comparing $>10$ to $0-2$ & & & 1.64 & $0.74,3.61$ \\
\hline \multicolumn{5}{|l|}{ Positive nodes } \\
\hline No & $54(52.9)$ & $300(73.5)$ & Ref* & \\
\hline Yes & $48(47.1)$ & $108(26.5)$ & 1.88 & $1.13,3.13$ \\
\hline \multicolumn{5}{|l|}{ Radiation to the axilla } \\
\hline No & $60(65.2)$ & $272(61.8)$ & Ref* & \\
\hline Yes & $32(34.8)$ & $107(28.2)$ & 1.10 & $0.62,1.93$ \\
\hline \multicolumn{5}{|l|}{ Chemotherapy } \\
\hline No & $40(40.0)$ & $208(49.9)$ & Ref* & \\
\hline Yes & $60(60.0)$ & $209(50.1)$ & 1.01 & $0.61,1.67$ \\
\hline \multicolumn{5}{|l|}{ Hormones therapy } \\
\hline No & $47(47.0)$ & $183(44.6)$ & Ref* & \\
\hline Yes & $53(53.0)$ & $227(55.4)$ & 0.92 & $0.58,1.46$ \\
\hline
\end{tabular}

$\mathrm{RR}=$ relative risk $\mathrm{CI}=$ confidence interval; $\mathrm{BMI}=$ body mass index

Note: Total number of subjects may not add up to 522 due to missing data

*Adjusted for age, axillary dissection, any radiation, and any radiation $\mathrm{x}$ axillary dissection

${ }^{\dagger}$ Adjusted for age, axillary dissection, chemotherapy, number of lymph nodes removed, any radiation, and any radiation $\mathrm{x}$ axillary dissection

*Adjusted for age, any radiation to axilla, axillary dissection, any radiation, and any radiation $\mathrm{x}$ axillary dissection

${ }^{\S}$ Among subjects who received radiation therapy
Table 4: Relative Risk of Arm Activities and Lymphedema Among Subjects Diagnosed with Breast Cancer in Iowa, 2004, Restricted to Women Who Reported no Change in Arm Activity Level Before and After Breast Cancer Diagnosis

\begin{tabular}{|l|c|c|c|c|c|c|}
\hline & \multicolumn{2}{|c|}{ Lymphedema } & \multicolumn{2}{c|}{ Crude } & \multicolumn{2}{c|}{ Adjusted } \\
\hline Arm activities & Yes & No & RR & CI & RR & CI \\
\hline Above the shoulders: $*$ & $9(20)$ & $35(13.3)$ & Ref & & Ref $^{\dagger}$ & \\
\hline High & $9(21.1)$ & $113(43)$ & 0.48 & $0.19,1.21$ & 0.51 & $0.19,1.40$ \\
\hline Medium & $14(48.9)$ & $115(43.7)$ & 0.74 & $0.31,1.76$ & 0.78 & $0.29,2.07$ \\
\hline Low & $22(48)$ & & & & \\
\hline Below the shoulders: $*$ & & & & & \\
\hline High & $18(40)$ & $126(47.9)$ & Ref & & Ref $^{\dagger}$ & \\
\hline Medium & $17(37.8)$ & $92(35)$ & 1.29 & $0.63,2.65$ & 1.38 & $0.63,3.01$ \\
\hline Low & $10(22.2)$ & $45(17.1)$ & 1.56 & $0.67,3.62$ & 1.59 & $0.60,4.24$ \\
\hline
\end{tabular}

$\mathrm{RR}=$ relative risk $\mathrm{CI}=$ confidence interval.

* Only included subjects that reported no change in arm activity level from before breast cancer diagnosis to after resuming household activities $(\mathrm{N}=308)$

${ }^{\dagger}$ Adjusted for BMI, age, axillary dissection, any radiation, and any radiation $\mathrm{x}$ axillary dissection

95\% CI: 3.07, 23.61). However, all but one participant developed arm infection after lymphedema diagnosis.

\section{Discussion}

The prevalence of arm lymphedema in women diagnosed with breast cancer in Iowa in 2004 was 19.5\% five-years after diagnosis, similar to results reported from previous studies $[4,12,13]$. This study, similar to other studies [14-19], found that BMI was associated with the development of lymphedema among these women. The association with increased BMI was evident both for the study definition of lymphedema and when defined only as physician-diagnosed cases. This suggests that the association seen was not an artifact of measurement error in lymphedema. Obesity, because of larger tissue volume and higher fat content, may have contributed to lymphedema development through increased difficulty of performing surgery or required alternative treatment techniques [20,21]. In addition, obesity may increase lymphatic stress by exacerbating the inflammatory response or prolonging the surgical healing time [22]. Moreover, the increased amount of adipose tissue may act as a reservoir for lymphatic fluids [20]. Furthermore, one small study found that weight loss was correlated with a significant reduction in arm volume [23]. Obesity is also linked to chronic conditions such as high blood pressure and diabetes, which may further impair a lethargic lymphatic system by disrupting fluid balance.

An increase in lymphedema risk was observed when both axillary dissection and radiation therapy were performed. A number of studies [24-29] have suggested that the addition of radiation therapy to axillary dissection increases the risk of lymphedema. Radiation after axillary dissection may have induced additional fibrosis that could compress or block lymphatic vessels. Participants in this study who had radiation and no axillary dissection were generally diagnosed with early stage breast cancer (stage I or II) and had less invasive treatments. Conversely, women who receive both axillary dissection and radiation therapy tended to be stage III and thus were treated more aggressively. This may further explain the interaction observed between axillary dissection and radiation therapy.

Overall, published reports have both supported [16,17,29-32] and refuted $[21,33,34]$ that increasing number of nodes excised is linked to arm lymphedema risk. This study did not find such an association after adjusting for axillary dissection. Axillary dissection was identified 
as a confounder because it was speculated that the association with the development of lymphedema may have been attributed to the intactness of the lymphatic network in the axilla rather than how many nodes were removed [30]. Axillary dissection is generally indicated in the presence of positive nodes and leads to an increased number of nodes excised. Axillary dissection, a procedure that disrupts the lymphatic network, remained associated with lymphedema even after adjusting for the number of lymph nodes removed. While breast cancer treatments are major contributors to lymphedema, the association between lymphedema and advance stages of cancer, positive nodes, or large tumors persisted even after adjusting for axillary dissection. It is possible that advanced disease or larger tumors may disrupt or damage regional lymphatics.

The presence of most chronic conditions did not influence the subsequent development of lymphedema. While it was speculated that conditions such as high blood pressure and diabetes may exacerbate a damaged lymphatic system due to increased hydrostatic pressure [35], we did not find such an association in this study. Medications taken to control high blood pressure [14], may have negated the effect of increased hydrostatic pressure. Both chronic bronchitis and kidney conditions were linked to the development of lymphedema. Kidney failure may be associated with fluid retention that may cause edema [35], thus further complicating an already delicate lymphatic system. It is also possible that these subjects may have a surveillance bias for physician-diagnosed lymphedema due to visiting the doctor for these other conditions. This study's findings are inconclusive since $<20$ subjects were diagnosed with these conditions. Arthritis and autoimmune diseases can contribute to lymphedema through inflammation to the joints, blood or lymph vessels, which may be reflected in the borderline association we saw.

While most of the previously published studies did not find an association between age and lymphedema, we, similar to Geller et al. [14], found younger age was associated with developing lymphedema. It has been suggested that younger women may have advanced cancer which required more invasive treatments [36]. This study found that younger women under the age of 50 were more likely to have positive nodes $(41 \%$ versus $19 \%)$ or be diagnosed at a higher stage after adjustment for confounders. They were also more likely to have axillary dissection. Moreover, younger women are more active outside of the home and may be more likely to notice the effects of mild lymphedema [37]. Also, older women tend to have extensive co-morbidity and might pay less attention to arm symptoms. Hence, arm symptoms related to lymphedema may have been under-reported by older women $[37,38]$. While this study attempted to capture arm lymphedema in both an objective and subjective way (based on arm symptoms experienced within the last three months), under-reporting of arm symptoms (subjective method) is an issue because subclinical cases of lymphedema may be missed.

Specific activities were not found to be associated with lymphedema. Among women who weight lifted, an increased amount of time spent weightlifting above the heart was not found to be associated with lymphedema. The results from this study were similar to another study in that none of the specific activities or overall arm activity level showed increased risk for lymphedema [39]. Arm lymphedema can lead to a reduction of arm activity level. In an attempt to avoid this bias, only subjects that reported no change in arm activity level both above and below the shoulders a year after resuming household activities (as compared to a year before breast cancer diagnosis) were included in the overall arm activity level analysis. With this restriction, arm activity level was not associated with lymphedema. However without this restriction, we found low level of arm activities below the shoulders was associated with lymphedema ( $R R=2.40,95 \% \mathrm{CI}: 1.38,4.20)$ (data not shown). We believe that this may be a reflection of decreased level of arm activity due to the presence of lymphedema. Overall, our findings on arm activity do not support an association with post-operative arm exercise and arm lymphedema.

Although air travel (41.6\% of our subjects) has been speculated by both clinicians and breast cancer survivors to be a potential risk factor for lymphedema, such an association was not observed in our study or the study by Kilbreath et al. [40]. It is probable that having lymphedema puts breast cancer survivors at risk for getting an arm infection due to decreased lymphatic circulation.

\section{Strengths}

This study was conducted using a population-based cohort of breast cancer survivors five to six years after breast cancer diagnosis, thereby avoiding erroneous inclusion of acute lymphedema cases. Participants reporting physician-diagnosed lymphedema were additionally asked if their condition has since resolved to decrease misclassification. Furthermore, objective and subjective assessments were applied to capture subclinical cases. Thirty-two percent of subjects reporting resolved lymphedema were later identified to have lymphedema through subclinical means. In addition, obtaining lymphedema status five or more years after breast cancer diagnosis allowed us to observe the long-term risk from treatments, as many studies have short followup times of 1-2 years after diagnosis or treatments.

\section{Limitations}

The biggest limitation was that all of our measures of lymphedema were self-reported. Due to caller identification and increased usage of cell phones, we were unable to reach as many subjects as we anticipated, and 181 eligible women could not be traced from ICR information.

\section{Conclusion}

Among this cohort of breast cancer survivors, we found lymphedema to have a prevalence of $19.5 \%$ five years after diagnosis, with most developing lymphedema within the first 2 years after surgery. In particular, women with a high BMI were found to be at risk for developing lymphedema, suggesting that obesity may further promote inflammation which can lead to lymphatic impairment. Younger age was also associated with lymphedema development. The combination of axillary dissection and radiation therapy doubled the risk of developing lymphedema. Low level of arm activity was not found to be associated with lymphedema.

\section{Authorship contribution}

All authors contributed to the conception, design, drafting, revision, and the final review of this manuscript.

\section{Funding}

This study was funded by the National Cancer Institute Grant Number: 5R03CA130031 (PI: Rebecca Tsai, PhD).

\section{References}

1. Siegel R, Ma J, Zou Z, Jemal A (2014) Cancer statistics, 2014. CA Cancer J Clin 64 9-29. [Crossref]

2. Surveillance Epidemiology and End Results (2018) SEER Stat fact sheets: breast http://seer.cancer.gov/statfacts/html/breast.html 
3. Noone AM, Howlader N, Krapcho M, Miller D, Brest A, et al. (2018) SEER Cancer Statistics Review, 1975-2015, National Cancer Institute. Bethesda, MD.

4. Velanovich V, Szymanski W (1999) Quality of life of breast cancer patients with lymphedema. Am J Surg 177: 184-187. [Crossref]

5. Kent H (1996) Breast-cancer survivors begin to challenge exercise taboos. CMAJ 155: 969-971. [Crossref]

6. Harris SR, Niesen-Vertommen SL (2000) Challenging the myth of exercise-induced lymphedema following breast cancer: a series of case reports. $J$ Surg Oncol 74: 95-8; discussion 8-9. [Crossref]

7. McKenzie DC, Kalda AL (2003) Effect of upper extremity exercise on secondary lymphedema in breast cancer patients: a pilot study. J Clin Oncol 21: 463-466. [Crossref]

8. Lee TS, Kilbreath SL, Sullivan G, Refshauge KM, Beith JM, et al. (2009) Factors that affect intention to avoid strenuous arm activity after breast cancer surgery. Oncol Nurs Forum 36: 454-462. [Crossref]

9. Harris SR (2012) "We're All in the Same Boat": A Review of the Benefits of Dragon Boat Racing for Women Living with Breast Cancer. Evid Based Complement Alternat Med 2012: 167651. [Crossref]

10. Baumann FT, Reike A, Reimer V, Schumann M, Hallek M, et al. (2018) Effects of physical exercise on breast cancer-related secondary lymphedema: a systematic review. Breast Cancer Res Treat. [Crossref]

11. Bloomquist K, Oturai P, Steele ML, Adamsen L, Moller T, et al. (2018) Heavy-Load Lifting: Acute Response in Breast Cancer Survivors at Risk for Lymphedema. Med Sci Sports Exerc 50: 187-195. [Crossref]

12. Petrek JA, Heelan MC (1998) Incidence of breast carcinoma-related lymphedema. Cancer 83: 2776-2781. [Crossref]

13. Sakorafas GH, Peros G, Cataliotti L, Vlastos G (2006) Lymphedema following axillary lymph node dissection for breast cancer. Surg Oncol 15: 153-165. [Crossref]

14. Geller BM, Vacek PM, O'Brien P, Secker-Walker RH (2003) Factors associated with arm swelling after breast cancer surgery. J Women's Health 12: 921-930. [Crossref]

15. Helyer LK, Varnic M, Le LW, Leong W, McCready D (2010) Obesity is a risk factor for developing postoperative lymphedema in breast cancer patients. Breast $J$ 16: 48-54. [Crossref]

16. Clark B, Sitzia J, Harlow W (2005) Incidence and risk of arm oedema following treatment for breast cancer: a three-year follow-up study. QJM 98: 343-348. [Crossref]

17. Dominick SA, Madlensky L, Natarajan L, Pierce JP (2013) Risk factors associated with breast cancer-related lymphedema in the WHEL Study. J Cancer Surviv 7: 115-123. [Crossref]

18. DiSipio T, Rye S, Newman B, Hayes S (2013) Incidence of unilateral arm lymphoedema after breast cancer: a systematic review and meta-analysis. Lancet Oncol 14: 500-515. [Crossref]

19. Ribeiro Pereira ACP, Koifman RJ, Bergmann A (2017) Incidence and risk factors of lymphedema after breast cancer treatment: 10 years of follow-up. Breast 36: 67-73. [Crossref]

20. Meric F, Buchholz TA, Mirza NQ, Vlastos G, Ames FC, et al. (2002) Long-term complications associated with breast-conservation surgery and radiotherapy. Ann Surg Oncol 9: 543-549. [Crossref]

21. Goffman TE, Laronga C, Wilson L, Elkins D (2004) Lymphedema of the arm and breas in irradiated breast cancer patients: risks in an era of dramatically changing axillary surgery. Breast $J$ 10: 405-411. [Crossref]

22. Ahmed RL, Schmitz KH, Prizment AE, Folsom AR (2011) Risk factors for lymphedema in breast cancer survivors, the Iowa Women's Health Study. Breast Cancer Res Treat 130: 981-991. [Crossref]
23. Shaw C, Mortimer P, Judd PA (2007) Randomized controlled trial comparing a low-fat diet with a weight-reduction diet in breast cancer-related lymphedema. Cancer 109: 1949-1956. [Crossref]

24. Kissin MW, Querci della Rovere G, Easton D, Westbury G (1986) Risk of lymphoedema following the treatment of breast cancer. Br J Surg 73: 580-584. [Crossref]

25. Schünemann H, Willich N (1998) Lymphoedema of the arm after primary treatment of breast cancer. Anticancer Res 18: 2235-2236. [Crossref]

26. Herd-Smith A, Russo A, Muraca MG, Del Turco MR, Cardona G (2001) Prognostic factors for lymphedema after primary treatment of breast carcinoma. Cancer 92: 17831787. [Crossref]

27. Kwan W, Jackson J, Weir LM, Dingee C, McGregor G, et al. (2002) Chronic arm morbidity after curative breast cancer treatment: prevalence and impact on quality of life. J Clin Oncol 20: 4242-4248. [Crossref]

28. Keramopoulos A, Tsionou C, Minaretzis D, Michalas S, Aravantinos D (1993) Arm morbidity following treatment of breast cancer with total axillary dissection: a multivariated approach. Oncology 50: 445-449. [Crossref]

29. Hinrichs CS, Watroba NL, Rezaishiraz H, Giese W, Hurd T, et al. (2004) Lymphedema secondary to postmastectomy radiation: incidence and risk factors. Ann Surg Oncol 11: 573-580. [Crossref]

30. Goldberg JI, Wiechmann LI, Riedel ER, Morrow M, Van Zee KJ (2010) Morbidity of sentinel node biopsy in breast cancer: the relationship between the number of excised lymph nodes and lymphedema. Ann Surg Oncol 17: 3278-3286. [Crossref]

31. Petrek JA, Senie RT, Peters M, Rosen PP (2001) Lymphedema in a cohort of breast carcinoma survivors 20 years after diagnosis. Cancer 92: 1368-1377. [Crossref]

32. Zou L, Liu FH, Shen PP, Hu Y, Liu XQ, et al. (2018) The incidence and risk factors of related lymphedema for breast cancer survivors post-operation: a 2-year follow-up prospective cohort study. Breast Cancer 25: 309-314. [Crossref]

33. Yen TW, Fan X, Sparapani R, Laud PW, Walker AP, et al. (2009) A contemporary, population-based study of lymphedema risk factors in older women with breast cancer Ann Surg Oncol 16: 979-988. [Crossref]

34. Beaulac SM, McNair LA, Scott TE, LaMorte WW, Kavanah MT (2002) Lymphedema and quality of life in survivors of early-stage breast cancer. Arch Surg 137: 1253-1257. [Crossref]

35. Paulus BM, Ali S, Zia AA, Munir A, Davis RC Jr, et al. (2008) Causes and consequences of systemic venous hypertension. Am J Med Sci 336: 489-497. [Crossref]

36. Paskett ED, Naughton MJ, McCoy TP, Case LD, Abbott JM (2007) The epidemiology of arm and hand swelling in premenopausal breast cancer survivors. Cancer Epidemiol Biomarkers Prev 16: 775-782. [Crossref]

37. Armer J, Fu MR (2005) Age differences in post-breast cancer lymphedema signs and symptoms. Cancer Nurs 28: 200-207. [Crossref]

38. Warmuth MA, Bowen G, Prosnitz LR, Chu L, Broadwater G, et al. (1998) Complications of axillary lymph node dissection for carcinoma of the breast: a report based on a patient survey. Cancer 83: 1362-1368. [Crossref]

39. Ahmed RL, Thomas W, Yee D, Schmitz KH (2006) Randomized controlled trial of weight training and lymphedema in breast cancer survivors. J Clin Oncol 24: 2765 2772. [Crossref]

40. Kilbreath SL, Ward LC, Lane K, McNeely M, Dylke ES, et al. (2010) Effect of air travel on lymphedema risk in women with history of breast cancer. Breast Cancer Res Treat 120: 649-654. [Crossref]

Copyright: (C2018 Tsai. This is an open-access article distributed under the terms of the Creative Commons Attribution License, which permits unrestricted use, distribution, and reproduction in any medium, provided the original author and source are credited. 